Bolm Inst. oceanogr., S Paulo, 25:131-155, 1976

\title{
SARDINELLA BRASILIENSIS: TIPO DE DESOVA, FECUNDIDADE E POTENCIAL REPRODUTIVO RELATIVO. I. ÁREA ENTRE $23^{\circ} 40^{\prime} \mathrm{S}$ E $24^{\circ} 20^{\prime} \mathrm{S}$, BRASIL*
}

\author{
A. E. A. de M. VAZZOLER \& C. L. D. B. ROSSI-WONGTSCHOWSKI** \\ Instituto Oceanográfico da Universidade de são Paulo
}

\section{SYNOPS IS}

This paper is a contribution to the knowledgment of some aspects of the reproduction of Sardinella brasiliensis (Steindachner, 1879) from the area between $23^{\circ} 40^{\prime} \mathrm{S}$ and $24^{\circ} 20^{\prime} \mathrm{S}$, Brazil. The individual spawning, fecundity, maturation and gonadal indexes, condition factor and spawning power, have been evaluated for the spawning periods of 1963-64 and 1964-65 and the results were statistically analysed. Fecundity/ total length, total weight, ovarian weight and body weight relations were determined for each period and the results statisticaly compared, showing significant differences between the periods under observation.

\section{INTRODUÇÃO}

A fecundidade constitui um parâmetro extremamente lābil, sofrendo grande influência de fatores intrínsecos (metabólicos) e de fatores extrínsecos (ambientais), refletindo a resultante da interação de ambos sobre o organismo individual. Varia acentuadamente entre populações distintas de uma mesma espécie e, dentro de cada grupo, entre períodos de reprodução sucessivos.

* Trabalho realizado com apoio financeiro da Fundação de Amparo à Pesquisa do Estado de São Paulo e do Conselho Nacional de Pesquisas.

** Bolsista da Fundação de Amparo à Pesquisa do Estado de São Paulo.

PUBL. NO 379 DO INST. OCEAN. DA USP. 
0 conhecimento da fecundidade de uma espécie e da amplitude de sua variação no espaço e no tempo, constitui elemento básico tanto para estudos puramente biológicos e ecológicos, como para aqueles que visam a estimativa dos estoques da espécie em questão.

Conhecimentos sobre fecundidade, quantidade de ovos na área de desova, 'sex-ratio' e estrutura da população num período de reprodução, permitem uma estimativa do volume do estoque naquele determinado período; tal estimativa é relativamente grosseira, pois não é considerada a taxa de fecundação, o que resulta numa sub-estimativa do estoque. Outros métodos que visam prever o volume do estoque em períodos futuros, com base no conhecimento da fecundidade em um dado período de desova anterior, apresentam maiores problemas, pois a estimativa das taxas de fecundação e de sobrevivência das sucessivas fases de desenvolvimento exige estudos profundos e de difícil execução, no campo, acompanhando a evolução da progênie resultante da referida desova.

Tais métodos só devem ser aplicados quando existe uma base sölida de conhecimentos sobre o processo de reprodução em sí, em sua integra.

Este trabalho refere-se a Sardinella brasiliensis (Steindachner, 1879) em parte de sua ārea de distribuição, visando evitar generalizações que poderiam não ser verdadeiras; pretende-se abranger outras sub-áreas em próximos trabalhos com base nos resultados do estudo da existência ou não de diversificação da espécie em sua área total de distribuição.

Este estudo tem por finalidade estabelecer o tipo de desova da espécie, obter uma estimativa dos indices de maturidade e gonadal, da fecundidade e suas correlações com outros parâmetros e do potencial reprodutivo relativo, bem como de suas variações entre períodos de desova. Visa, principalmente, mostrar que relações e índices obtidos através de tratamento matemático dos dados são úteis para quantificar um processo num dado período, mas não podem ser considerados como definitivos para a espécie, uma vez que se referem a fenômenos biológicos, portanto de amplitude variāvel, intimamente relacionados às condições ambientais. 


\section{MATERIAL E MÉTODOS}

Os exemplares utilizados neste estudo foram coletados da captura de barcos de pesca comercial, com base no Entreposto de Pesca de Santos, que operaram no litoral do Estado de São Paulo, na ārea entre a Ilha da Vitória $\left(23^{\circ} 40^{\prime} \mathrm{S}\right)$ e Laje de Santos $\left(24^{\circ} 20^{\prime} \mathrm{S}\right)$ (Fig. 1).

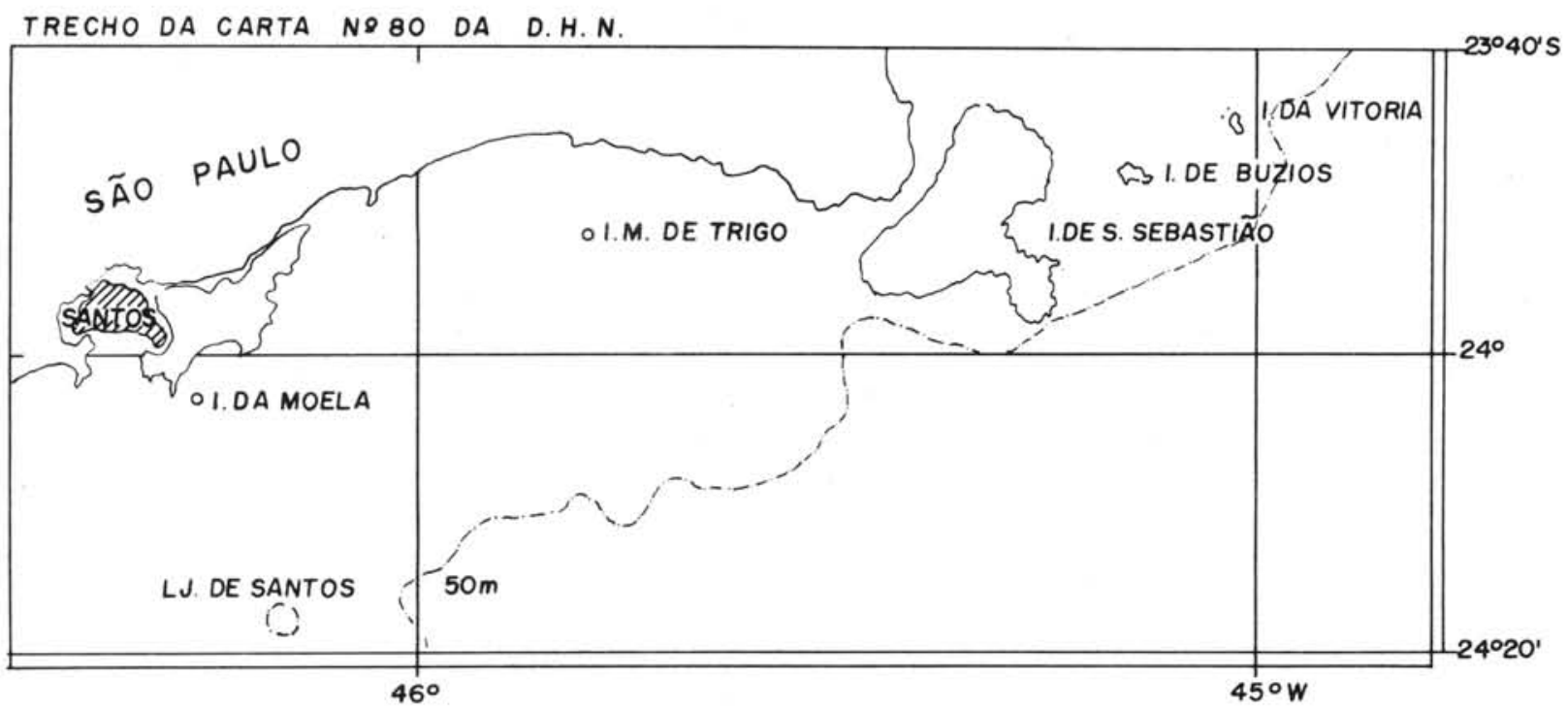

Fig. 1 - Mapa da região estudada, indicando os locais de coleta das amostras.

Foram considerados os períodos de desova de 1963-64 e de 1964-65, que se estende de outubro a março (Moraes, 1963; Vazzoler \& Vazzoler, 1965).

Foram examinados 834 exemplares durante o período 1963-64 e 1051 durante 1964-65, dos quais foram anotados dados sobre:

a) comprimento total: medido de 0,5 em 0,5 cm com grupamento dos valores intermediārios na classe imediatamente inferior;

b) peso tota1: em gramas;

c) sexo;

d) estādio de maturidade. 
Foram selecionadas 58 fêmeas durante o período de desova de 1963-64 e 105 fêmeas durante 1964-65, cujos ovārios encontravam-se maduros (estādio $C$ ), mas não totalmente, para evitar o risco de jā ter ocorrido desova de parte dos óvulos. Os ovārios, neste estādio, apresentam-se tūrgidos, sem vascularização, com óvulos bem visíveis a olho nú, grandes, alguns jā translúcidos.

Os intervalos de comprimento total e peso total abrangidos foram de 19,0 a $23,0 \mathrm{~cm}$ e 49,0 a $106 \mathrm{~g}$, respectivamente. Dessas fêmeas foram retirados os ovārios e pesados em gramas, com aproximação até centígramas; suas membranas foram seccionadas longitudinalmente e colocados em solução de Gilson modificada (Simpson, 1951). O procedimento seguinte e os métodos usados para obtenção das distribuições de freqüência dos diâmetros dos óvulos e estimativa do número total de óvulos nas gônadas, e da fecundidade, para cada exemplar, estão descritos em Vazzoler (1963).

Os ovārios encontravam-se em diferentes fases dentro do estādio $C$; assim sendo, para estimativa da fecundidade absoluta (Nikolskii, 1969; Ciechomski, 1967) de cada peixe foram considerados os óvulos com diâmetro superior a: (vide Fig. 2)

a) fases $C_{1}$ e $C_{2} \ldots \ldots .253,11 \mu$

b) fase $\mathrm{C}_{3} \ldots \ldots \ldots \ldots .337,48 \mu$

c) fase $C_{4} \ldots \ldots \ldots \ldots .421,85 \mu$

d) fase $C_{5} \ldots \ldots \ldots \ldots 506,22 \mu$, que completariam seu desenvolvimento e seriam eliminados durante a desova.

Os dados referentes às 58 fêmeas examinadas durante 1963-64 e às 105 durante 1964-65 encontram-se arquivados no Departamento de Oceanografia Biológica do Instituto Oceanográfico da Universidade de São Paulo.

As distribuições individuais de freqüência dos diâmetros dos óvulos foram grupados segundo a posição da moda mais avançada (óvulos mais desenvo1vidos) como já descrito em trabalhos anteriores (Vazzoler 1963, 1969), estando os resultados mostrados na Tabela I e representados graficamente na Figura 2. 
TABELA I - Distribuições de freqüência dos diâmetros dos óvulos de gônadas nas cinco fases de desenvolvimento, dentro do estädio $C$

\begin{tabular}{cccccc}
\hline $\begin{array}{c}\text { Diâmetro dos } \\
\text { óvulos }(\mu)\end{array}$ & $\mathrm{C}_{1}(\%)$ & $\mathrm{C}_{2}(\%)$ & $\mathrm{C}_{3}(\%)$ & $\mathrm{C}_{4}(\%)$ & $\mathrm{C}_{5}(\%)$ \\
\hline 168,74 & 12,8 & 5,5 & 2,3 & 2,4 & - \\
253,11 & 24,1 & 10,3 & 6,9 & 8,2 & 10,0 \\
337,48 & 47,4 & 23,6 & 13,3 & 13,2 & 17,0 \\
421,85 & 15,6 & 46,4 & 25,3 & 10,0 & 10,0 \\
506,22 & - & 13,8 & 47,5 & 48,6 & 4,0 \\
590,69 & - & 0,4 & 4,7 & 17,0 & 16,0 \\
674,96 & - & - & - & 0,5 & 38,0 \\
759,33 & - & - & - & - & 5,0 \\
\hline $\begin{array}{c}\text { No de fêmeas } \\
\text { examinadas }\end{array}$ & 8 & 70 & 78 & 6 & 1 \\
\hline
\end{tabular}

A partir dos dados sobre comprimento total $\left(\mathrm{L}_{t}\right)$, peso total $\left(\mathrm{W}_{t}\right)$, peso das gônadas $\left(W_{g}\right)$ e peso do corpo $\left(W_{C}\right)$ (peso total menos o das gônadas) foram calculados os índices gonadal e de maturidade, para cada fêmea.

0 indice gonadal $\left(\mathrm{I}_{\mathrm{g}}\right)$ expressa a relação entre o peso das gônadas e o cubo do comprimento total, tendo sido os resultados multiplicados por $10^{4}$ para facilitar a anālise; o índice de maturidade ( $I_{m}$ ) expressa a relação entre o peso das gônadas e o peso do corpo, tendo sido os resultados multiplicados por $10^{3}$ pelo mesmo motivo anterior:

$$
I_{g}=\frac{W_{g}}{L_{t}^{3}} \cdot 10^{4} \quad I_{m}=\frac{W_{g}}{W_{c}} \cdot 10^{3}
$$

Os valores dos índices gonadal e de maturidade foram grupados segundo a fase em que se encontrava a gônada do exemplar, e os dados foram analisados estatisticamente, calculando-se as médias, seus desvios padrão e intervalos de confiança (Tab. II, Figs 3-6). Os resultados foram testados dentro de cada período entre as vārias fases (teste "F") e entre períodos dentro de cada fase (teste de "t") (Tab. III). 
Bolm Inst. oceanogr., S Paulo, 25, 1976

TABELA II - Resultados da anālise estatística dos índices gonadais e índices de maturidade de fêmeas nas värias fases do estädio $C$, para os períodos de desova de 1963-64 e 1964-65

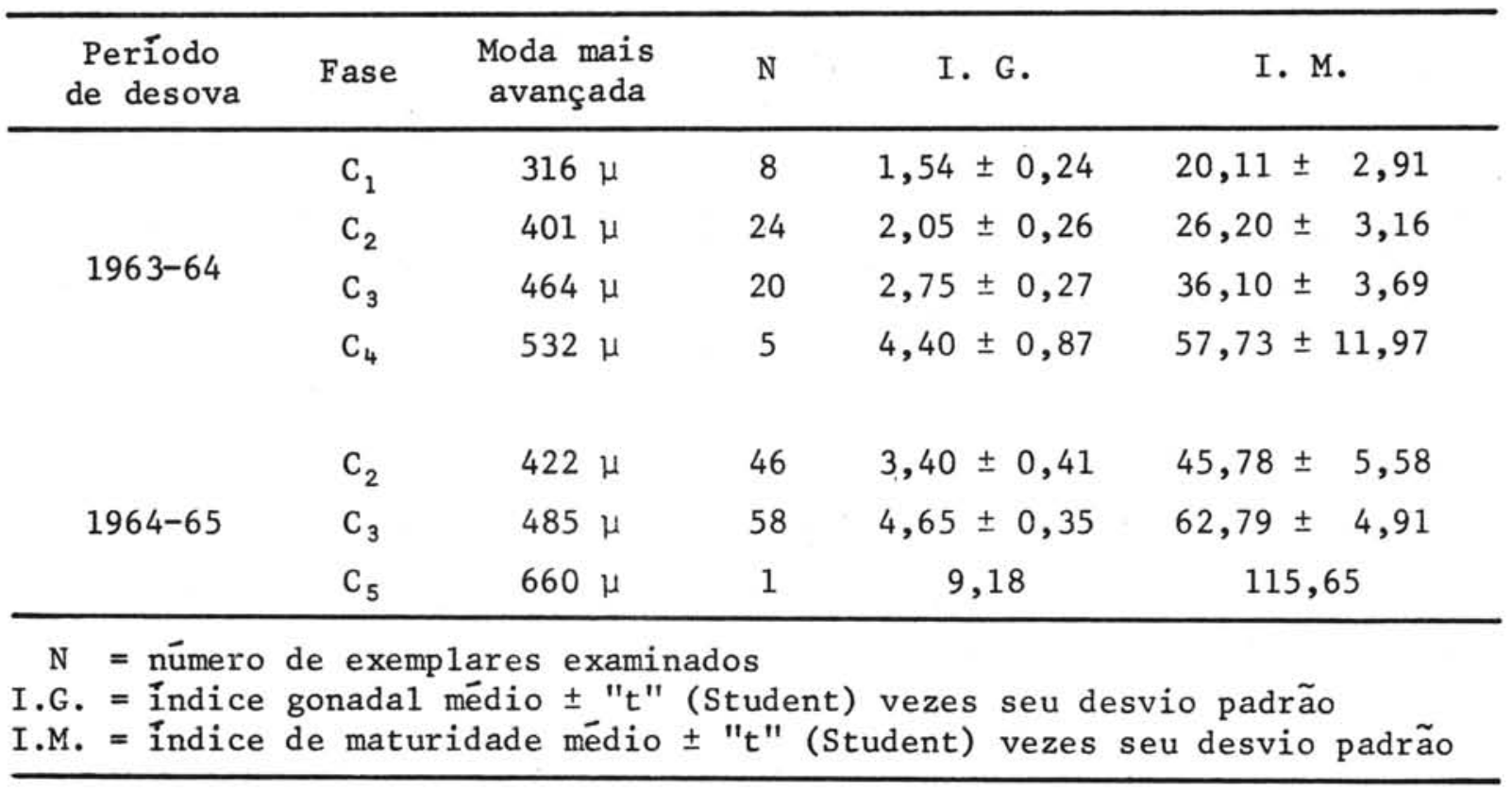

TABELA III - Resultados dos testes entre os valores dos índices gonadais mëdios e índices de maturidade médios dentro de cada período de desova e entre períodos de desova

\begin{tabular}{|c|c|c|c|c|c|}
\hline \multirow{2}{*}{ Teste entre } & \multirow[b]{2}{*}{$\mathrm{n}$} & \multicolumn{2}{|c|}{ "F" } & \multicolumn{2}{|c|}{ "t" } \\
\hline & & I. G. & I. M. & I. G. & I. M. \\
\hline$C_{1} \times C_{2} \times C_{3} \times C_{4}(1963-64)$ & 57 & $31,21 *$ & $33,69 *$ & - & - \\
\hline$C_{2} \times C_{3} \times C_{5}(1964-65)$ & 105 & $17,96 *$ & $15,94 *$ & - & - \\
\hline$C_{2}(1963-64) \times C_{2}(1964-65)$ & 70 & - & - & $4,56 *$ & $4,91 *$ \\
\hline$C_{3}(1963-64) \times C_{3}(1964-65)$ & 78 & - & - & $6,22 *$ & $6,24 *$ \\
\hline \multicolumn{6}{|c|}{$\begin{aligned} \mathrm{n} & =\text { numero total de exemplares } \\
" \mathrm{~F} " & =\text { valor de "F" obtido no teste entre } \\
" t " & =\text { valor de "t" obtido entre períodos } \\
* & =\text { significativo ao nivel de } 0,1 \%\end{aligned}$} \\
\hline
\end{tabular}


Aos dados de fecundidade (F), comprimento total, peso total, peso das gônadas e peso do corpo foram ajustadas equações de retas do 19 grau, através do método dos mínimos quadrados, para cada período de desova (Tab. IV), e os resultados testados atravēs do teste de "t" (Tab. V). As retas de regressão representativas das relações entre $F \times L_{t}, F \times W_{t}, F \times W_{g}$ e $F \times W_{c}$ estão mostradas nas Figuras $7 \mathrm{~A}-\mathrm{D}$, para cada período estudado.

Aos dados sobre peso $\left(W_{t}\right)$ e comprimento $\left(\bar{L}_{t}\right)$ totais médios de fêmeas, durante cada um dos períodos considerados foram ajustadas equações do tipo $\mathrm{W}_{\mathrm{t}}=\mathrm{a} \mathrm{L}_{\mathrm{t}}^{\mathrm{b}}$, atravēs do método dos mínimos quadrados, após transformação logarítmica, estando os resultados mostrados na Tabela VI e as curvas representativas da relação, na Figura 8 .

Dos dados sobre comprimento total e sexo dos exemplares examinados durante cada período foram obtidas as distribuições porcentuais de freqüência de comprimentos para as fêmeas, e respectivo comprimento médio, em cada período de desova (Fig. 9).

TABELA IV - Dados das regressões entre fecundidade (F; milhares de övulos) e a) comprimento total $\left(L_{t} ; \mathrm{cm}\right)$, b) peso total $\left(W_{t} ; g\right)$, c) peso das gônadas $\left(W_{g} ; g\right)$ e d) peso do corpo $\left(W_{c} ; g\right)$, por período de desova estudado

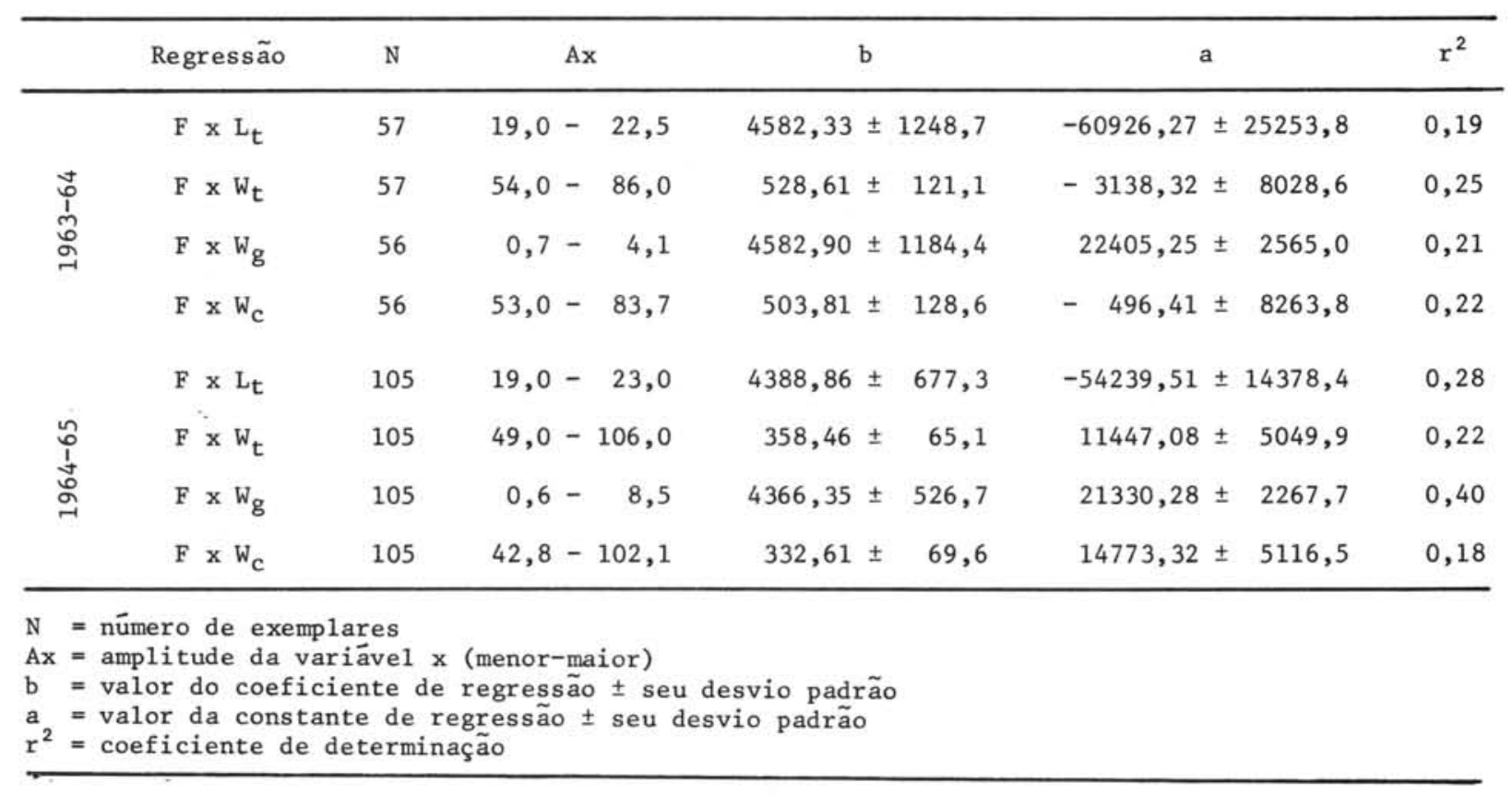


TABELA V - Resultados do teste de " $t$ " aplicado às regressões entre períodos

\begin{tabular}{cccc}
\hline Regressão entre & $\mathrm{n}$ & $\mathrm{t}(\mathrm{b})$ & $\mathrm{t}(\mathrm{a})$ \\
\hline $\mathrm{F} \times \mathrm{L}_{\mathrm{t}}$ & 162 & 0,098 & $375,70 *$ \\
$\mathrm{~F} \times \mathrm{W}_{\mathrm{t}}$ & 162 & 0,866 & $875,30 *$ \\
$\mathrm{~F} \times \mathrm{W}_{\mathrm{c}}$ & 161 & 0,117 & $58,27 *$ \\
$\mathrm{~F} \times \mathrm{W}_{\mathrm{g}}$ & 161 & 0,844 & $910,21 *$ \\
\hline
\end{tabular}

$\mathrm{n}=$ número total de exemplares

* = significativo ao nível de $0,1 \%$

TABELA VI - Dados das regressões entre logarítmo natural do peso total $\left(1, \bar{W}_{t}\right)$ médio e logarítmo natural do comprimento total $\left(1_{n} \bar{L}_{t}\right)$ médio, para fêmeas, por período estudado

\begin{tabular}{ccc}
\hline Período & $1963-64$ & $1964-65$ \\
\hline $\mathrm{N}$ & 9 & 9 \\
$\mathrm{Ax}$ & $19-22$ & $19-22$ \\
$\mathrm{~b}$ & $2,3597 \pm 0,1175$ & $2,4816 \pm 0,0798$ \\
$\mathrm{a}$ & $-2,9162 \pm 0,3518$ & $-3,2667 \pm 0,2390$ \\
$\mathrm{r}^{2}$ & 0,9829 & 0,9927 \\
\hline
\end{tabular}

$\mathrm{N}=$ número de classes

$\mathrm{Ax}=$ amplitude da variável $\mathrm{x}$ (menor-maior)

$\mathrm{b}=$ valor, em $1_{\mathrm{n}}$, do coeficiente de regressão \pm seu desvio padrão

a $=$ valor, em $1_{n}$, da constante de regressão \pm seu desvio padrão

$\mathrm{r}^{2}=$ coeficiente de determinação 
A partir dos dados de distribuição de freqüência de comprimento e dos pesos totais estimados para cada classe de comprimento, calculou-se o peso médio por fêmea, para cada período estudado.

Considerando-se, para cada período, os valores de comprimento médio e peso médio por fêmea, calculou-se o fator de condição (Vazzoler \& Vazzoler, 1965) médio da população $(\overline{\mathrm{K}})$, sendo:

$$
\overline{\mathrm{K}}=\frac{\overline{\mathrm{W}}_{\mathrm{t}}}{\overline{\mathrm{L}}_{\mathrm{t}}^{3}} \cdot 10^{3}
$$

A partir das freqüências relativas de fêmeas por classe de comprimento e dos valores estimados da fecundidade por classe de comprimento, para cada período de desova, calculou-se o potencial reprodutivo relativo a 100 fêmeas da população (Fontana \& LeGuen, 1969), e a fecundidade média por fêmea (Fig. 10).

\section{RESULTADOS}

As 58 fêmeas estudadas para o período de desova de 1963-64 e as 105 fêmeas para 1964-65, apesar de maduras, com ovários no estādio $C$, não tinham atingido todas o mesmo grau de desenvolvimento, encontrando-se em fases distintas dentro desse estádio. Esse fato foi mostrado pela anālise das distribuições individuais de freqüência dos diâmetros dos óvulos das gônadas acima referidas; o tamanho máximo atingido pelos óvulos, nessas gônadas, variou entre 421,85 e 759,33 micra (Fig. 2).

As modas mais avançadas (correspondentes ao grupo de óvulos maiores, mais desenvolvidos) mostram-se em cinco posições diferentes, considerando-se os dois períodos de desova, sendo que essas posições constituem a base para a caracterização de cinco fases distintas dentro do estádio $C: C_{1}, C_{2}, C_{3}$, $\mathrm{C}_{4}$ e $\mathrm{C}_{5}$.

Durante o período de desova de 1963-64, ocorreram gônadas nas fases seguintes, com moda mais avançada em: 
a) $c_{1} \ldots \ldots \ldots 316 \mu$

b) $\mathrm{C}_{2} \ldots \ldots \ldots 401 \mu$

c) $\mathrm{C}_{3} \ldots \ldots \ldots 464 \mu$

d) $\mathrm{C}_{4} \ldots \ldots \ldots \ldots 532 \mu$

No período 1964-65, ocorreram:

a) $\mathrm{C}_{2} \ldots \ldots \ldots 422 \mu$

b) $\mathrm{C}_{3} \ldots \ldots \ldots 484 \mu$

c) $\mathrm{C}_{5} \ldots \ldots \ldots 660 \mathrm{~m}$

As distribuições de freqüência dos diâmetros dos óvulos grupados para os dois períodos de desova, segundo a fase em que se encontravam as gônadas (Fig. 2), mostram o desenvolvimento dos óvulos dentro do período de desova. Observa-se que os óvulos que seriam eliminados apresentam diâmetros variáveis nas distintas fases; em $\mathrm{C}_{1}$ ocorre apenas um grupo de óvulos com valor modal de $316 \mu$, que evolui atingindo em $\mathrm{C}_{5}, 660 \mu$. Um grupo de $316 \mu$ permanece em $\mathrm{C}_{5}$, sugerindo constituir grupo que irá desenvolver-se apenas no período de desova seguinte.

As fêmeas em fase $C_{5}$ apresentam óvulos com diâmetro máximo de $760 \mu$, o que indica que deviam estar aptas a desovar, pois o ovo dessa espécie apresenta diâmetro médio de $1.180 \mu$ (Matsuura, 1971), tendo sofrido aumento de tamanho devido aos processos que seguem-se à fecundação.

Os resultados sugerem que a desova é total, ou seja, que cada indivỉduo desova apenas uma vez dentro de cada período, mas nem todos os indivíduos desovam na mesma época, o que é reforçado pela ocorrência, na população, de indivíduos em diferentes fases do estádio $C$.

Comparando-se os valores dos índices gonadais médios entre os dois períodos, por fase (Fig. 3) ou por valor da moda mais avançada de cada fase (Fig. 4), observa-se que os do período 1964-65 são mais elevados. Tais valores para cada fase, entre períodos, são significativamente diferentes entre sỉ (Tab. III). A variação dos índices dentro de um mesmo período é bem acentuada, sendo que ocorrem diferenças significativas entre os mesmos (Tab. III), dentro dos dois períodos. 

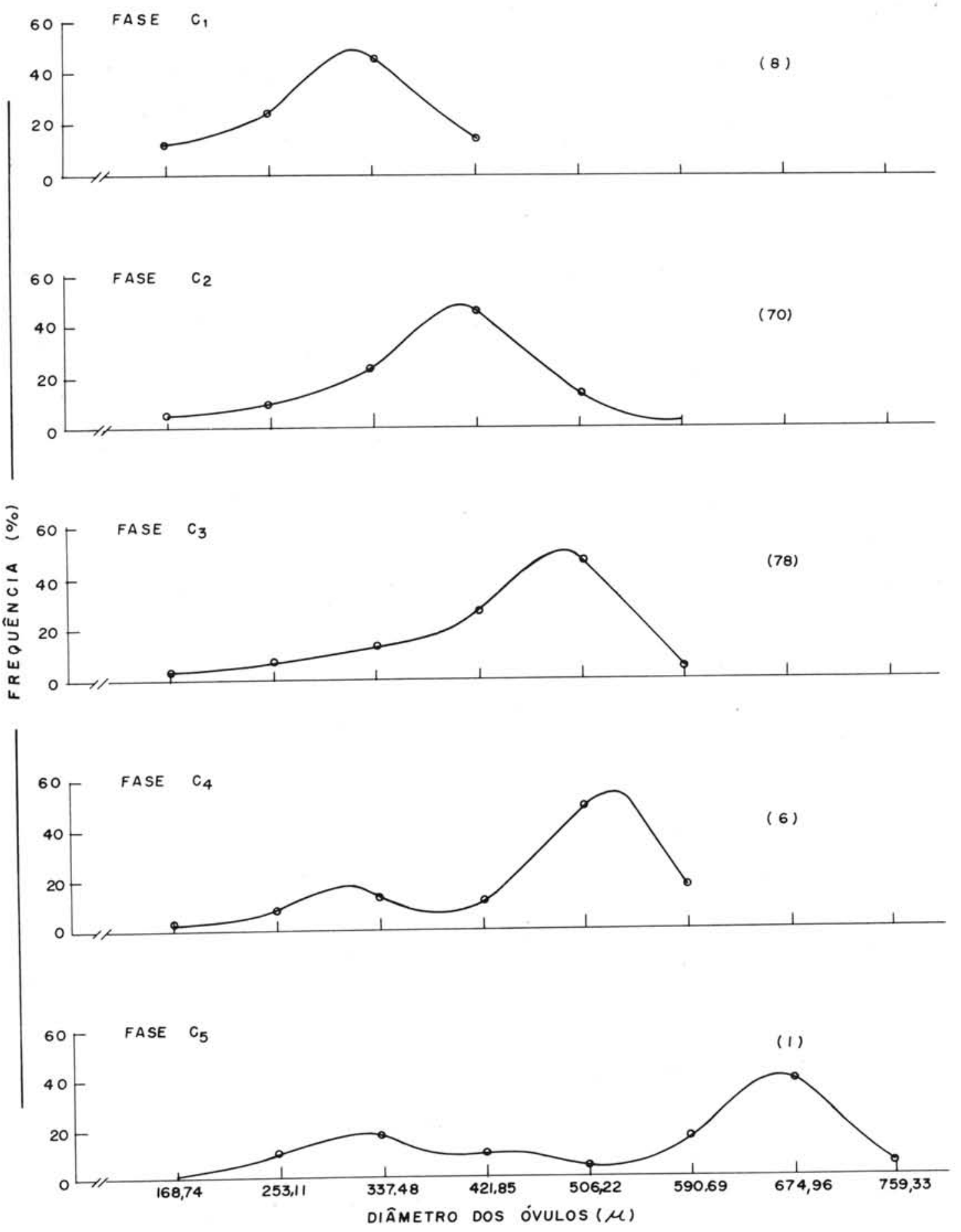

Fig. 2 - Curvas representativas das distribuições de freqüência dos diâmetros dos övulos de gônadas nas cinco fases de desenvolvimento, dentro do estádio $C$, para os dois períodos de desova estudados, grupados.

( ) = Nümero de exemplares considerados. 


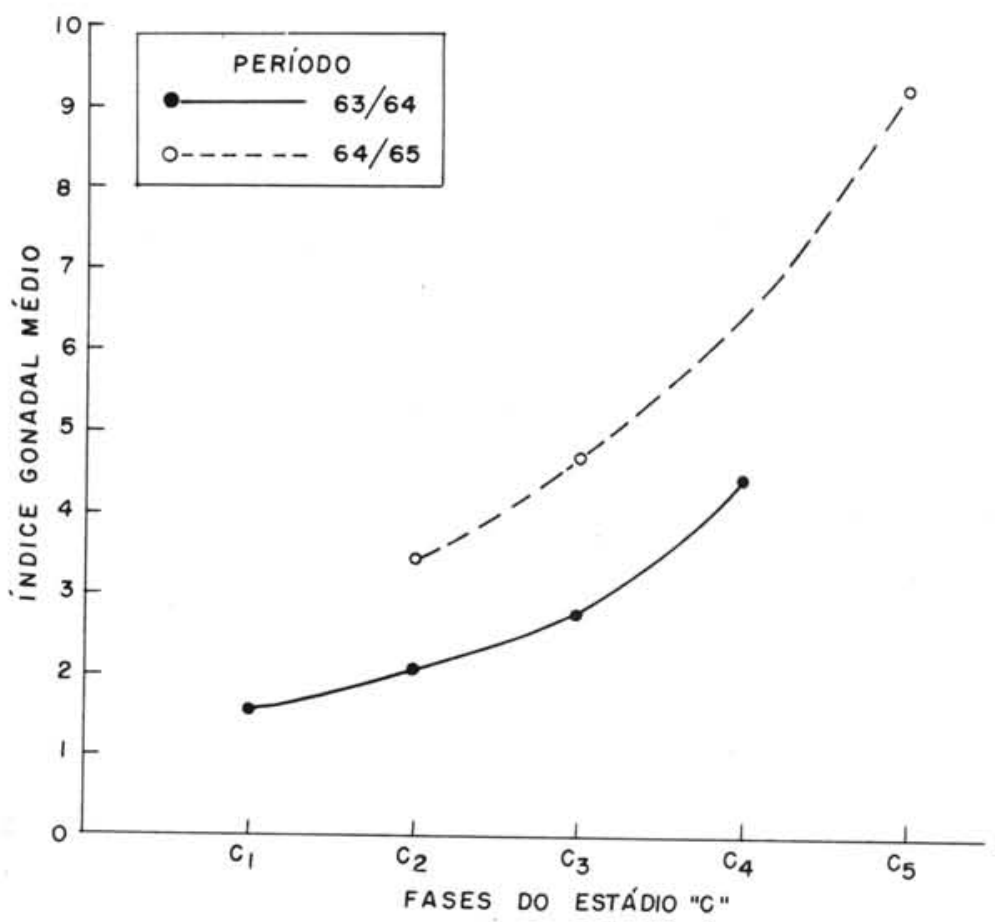

Fig. 3 - Representação gräfica da variação dos índices gonadais mëdios, por fase, durante os períodos de desova de 1963-64 e 1964-65.

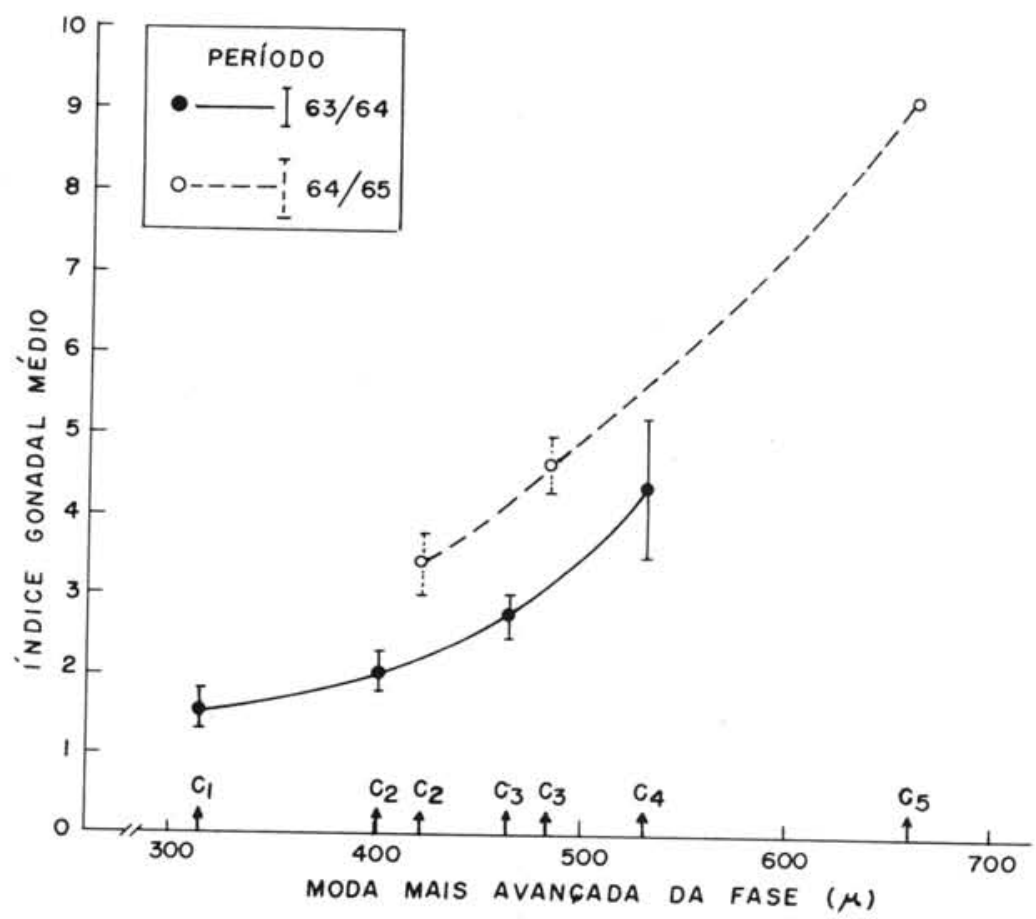

Fig. 4 - Representação gräfica da variação dos índices gonadais mēdios com as modas mais avançadas de cada fase, e seus intervalos de confiança, durante os períodos de desova de 1963-64 e 1964-65. 
0 mesmo ocorre quando comparamos os valores dos índices de maturidade médios, que também se apresentam mais elevados para o período 1964-65 (Figs 5-6). Tais valores são significativamente diferentes dentro de cada fase entre períodos e dentro de cada período entre fases (Tab. III).

As retas representativas das relações entre fecundidade e comprimento total (Fig. 7-A) mostram que a fecundidade relativa por classe de comprimento foi mais elevada durante o período 1964-65. Considerando-se a relação fecundidade $x$ peso total (Fig. 7-B), observa-se que até $86 \mathrm{~g}$ de peso total, a fecundidade relativa por classe de peso foi mais elevada durante 1964-65; a partir de $86 \mathrm{~g}$ há uma inversão. Para a relação fecundidade $x$ peso das gônadas (Fig. 7-C) a fecundidade foi mais elevada durante o período 1963-64, enquanto que para fecundidade $x$ peso do corpo (Fig. 7-D), ocorre intersecção das retas no ponto correspondente a $91 \mathrm{~g}$; abaixo desse ponto, a fecundidade relativa foi mais elevada para o período 1964-65.

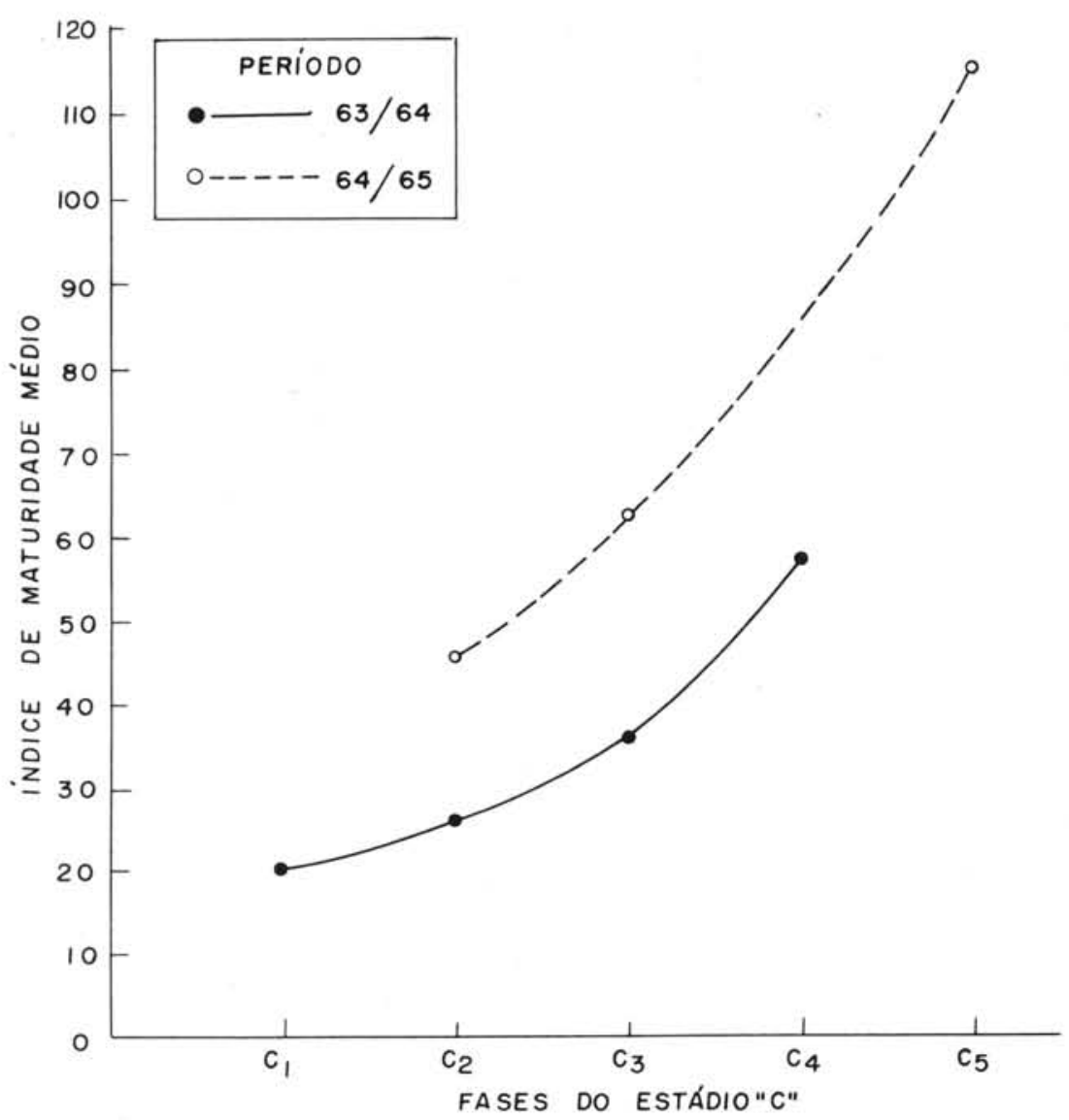

Fig. 5 - Representação gräfica da variação dos índices de maturidade mëdios, por fase, durante os períodos de desova de 1963-64 e 1964-65. 


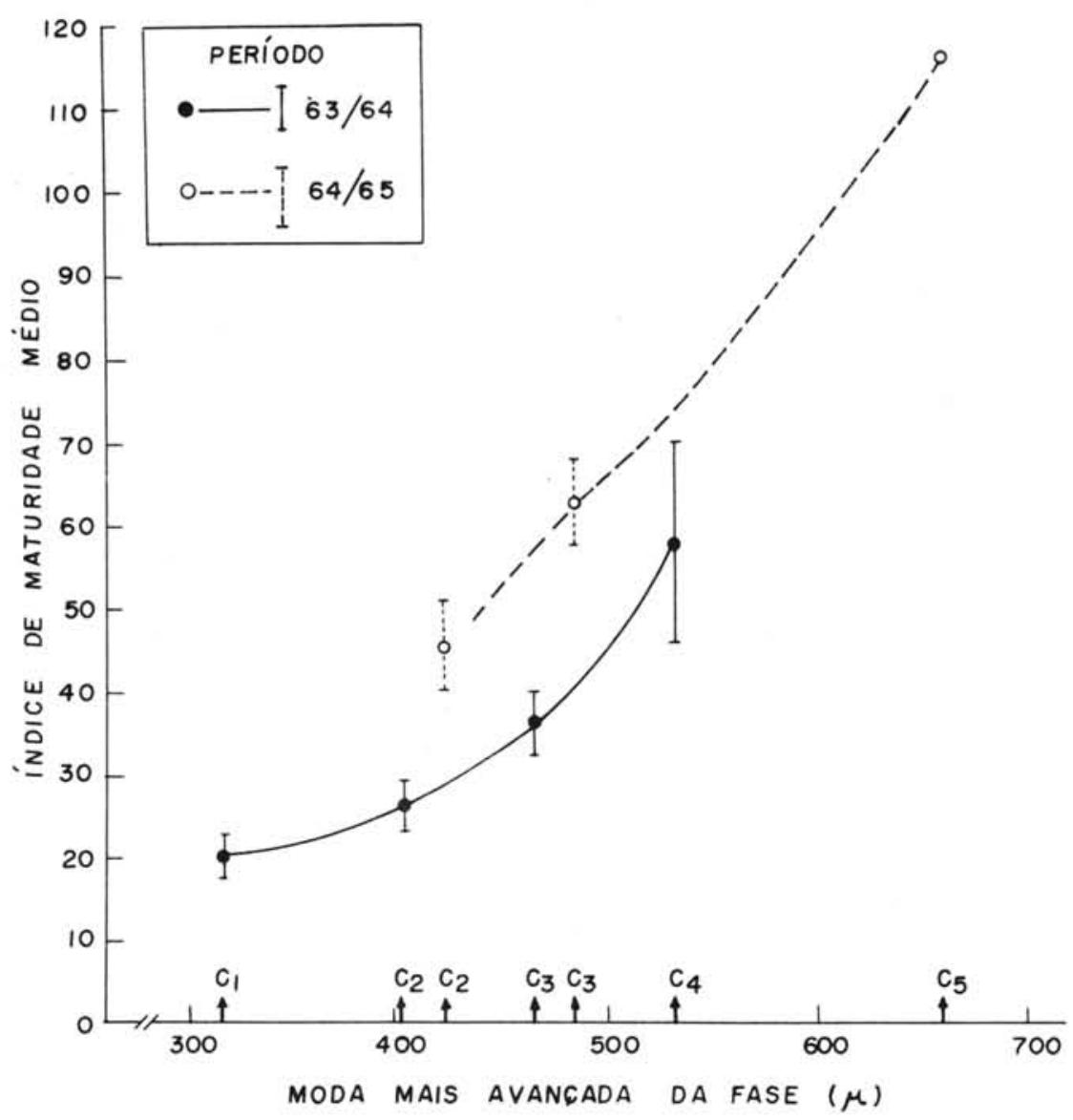

Fig. 6 - Representação gräfica da variação dos îndices de maturidade médios com as modas mais avançadas de cada fase, e seus intervalos de confiança, durante os perf́lodos de 1963-64 e 1964-65.

A variação dos valores dos coeficientes de determinação para as diferentes relações durante os dois períodos (Tab. IV) mostra que não há um parâmetro, determinado, com influência principal sobre a fecundidade, mas sim uma interação de vārios fatores, alēm dos parâmetros considerados, que atuam sobre a mesma.

Testando-se as relações entre fecundidade e cada parâmetro estudado, entre os dois períodos verifica-se que há diferenças significativas para as quatro relações (Tab. V).

Os pesos totais médios das fêmeas por classe de comprimento foram mais elevados durante o período 1964-65 (Fig. 8). Nesse período também o valor do fator de condição médio da população foi mais elevado, tendo sido de 7,83 para $1963-64$ e de 8,00 para 1964-65. 

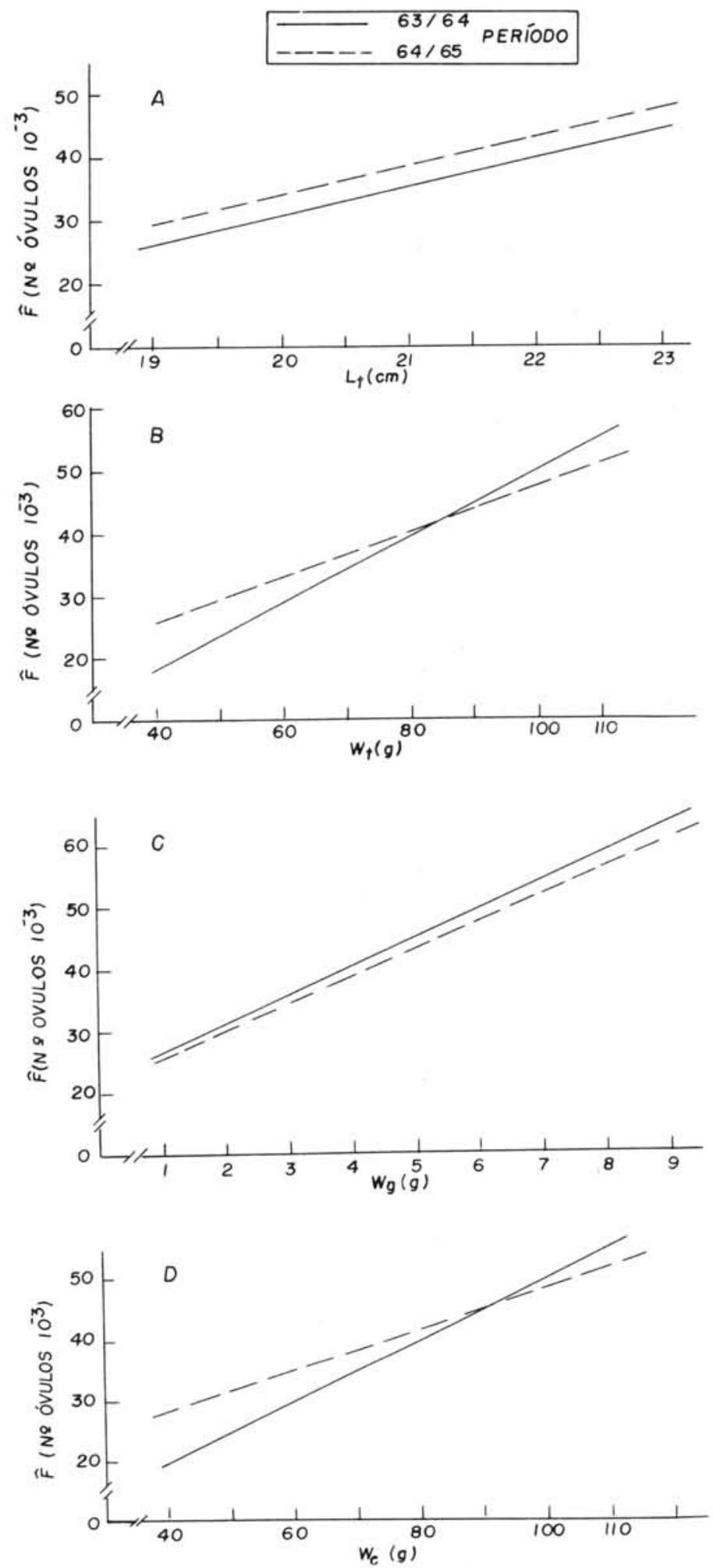

Fig. 7 - Retas representativas das regressões entre: A) fecundidade e comprimento total, B) fecundidade e peso total, C) fecundidade e peso das gônadas e D) fecundidade e peso do corpo. 


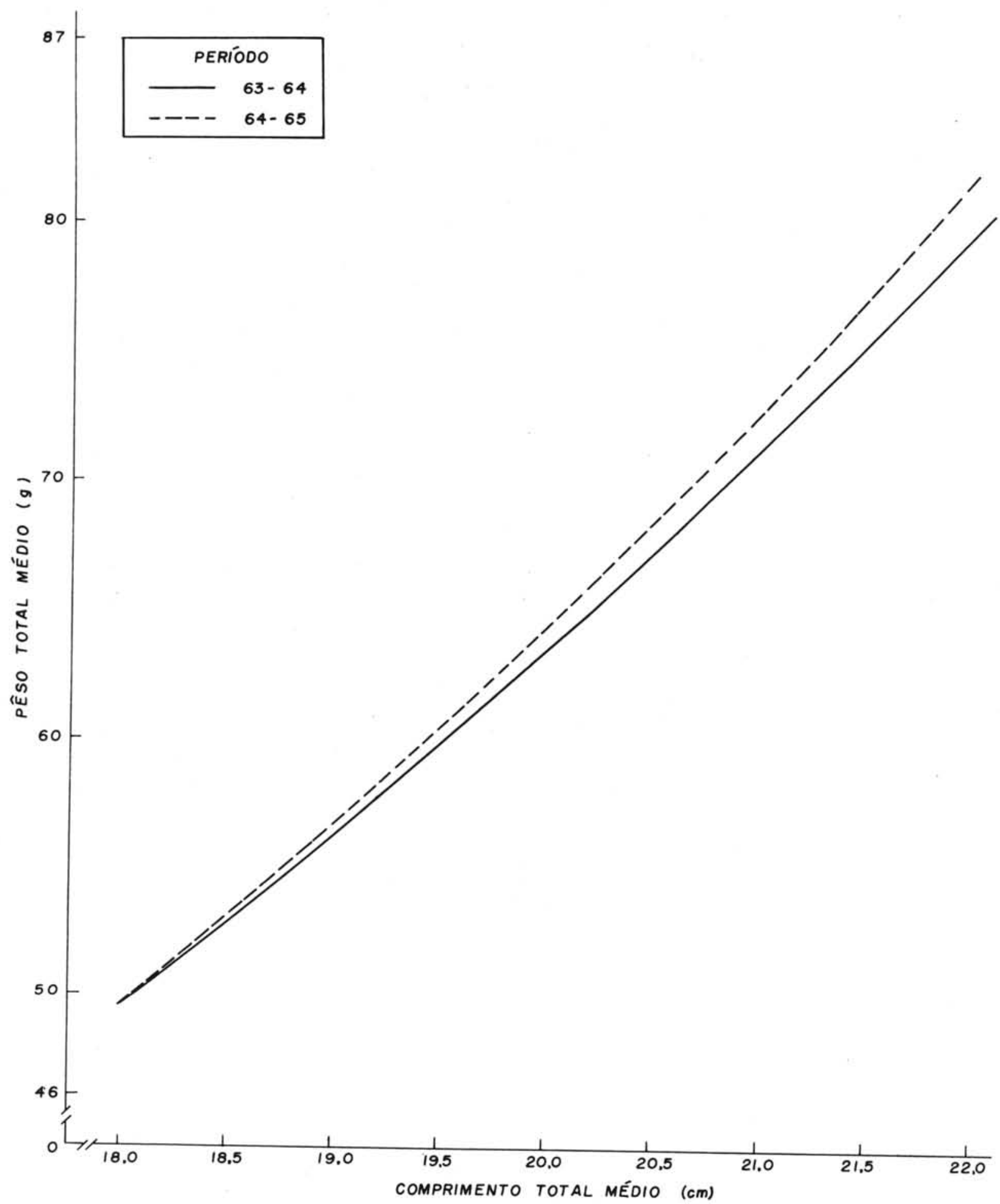

Fig. 8 - Curvas representativas da relação entre peso mëdio $\left(\bar{W}_{t}\right)$ e comprimento médio $\left(\bar{L}_{t}\right)$ para fêmeas, durante os períodos de desova de $1963-64$ e $1964-65$. 
As distribuições porcentuais de freqüências de fêmeas por classe de comprimento para os dois períodos (Fig. 9) mostram que houve alteração da estrutura da população de um período para outro. Em 1963-64 ocorreram fêmeas entre 17 e $22 \mathrm{~cm}$, com comprimento médio de $20,13 \mathrm{~cm}$, enquanto que em 1964-65 a distribuição foi mais ampla abrangendo de 17 a $24 \mathrm{~cm}$, com comprimento médio de $20,63 \mathrm{~cm}$.

0 potencial reprodutivo relativo a 100 fêmeas (Fig. 10) foi mais elevado para o período 1964-65, sendo o valor médio da fecundidade $(\bar{F})$ por fêmea, de 31.380 óvulos em $1963-64$ e de 36.110 óvulos em 1964-65.

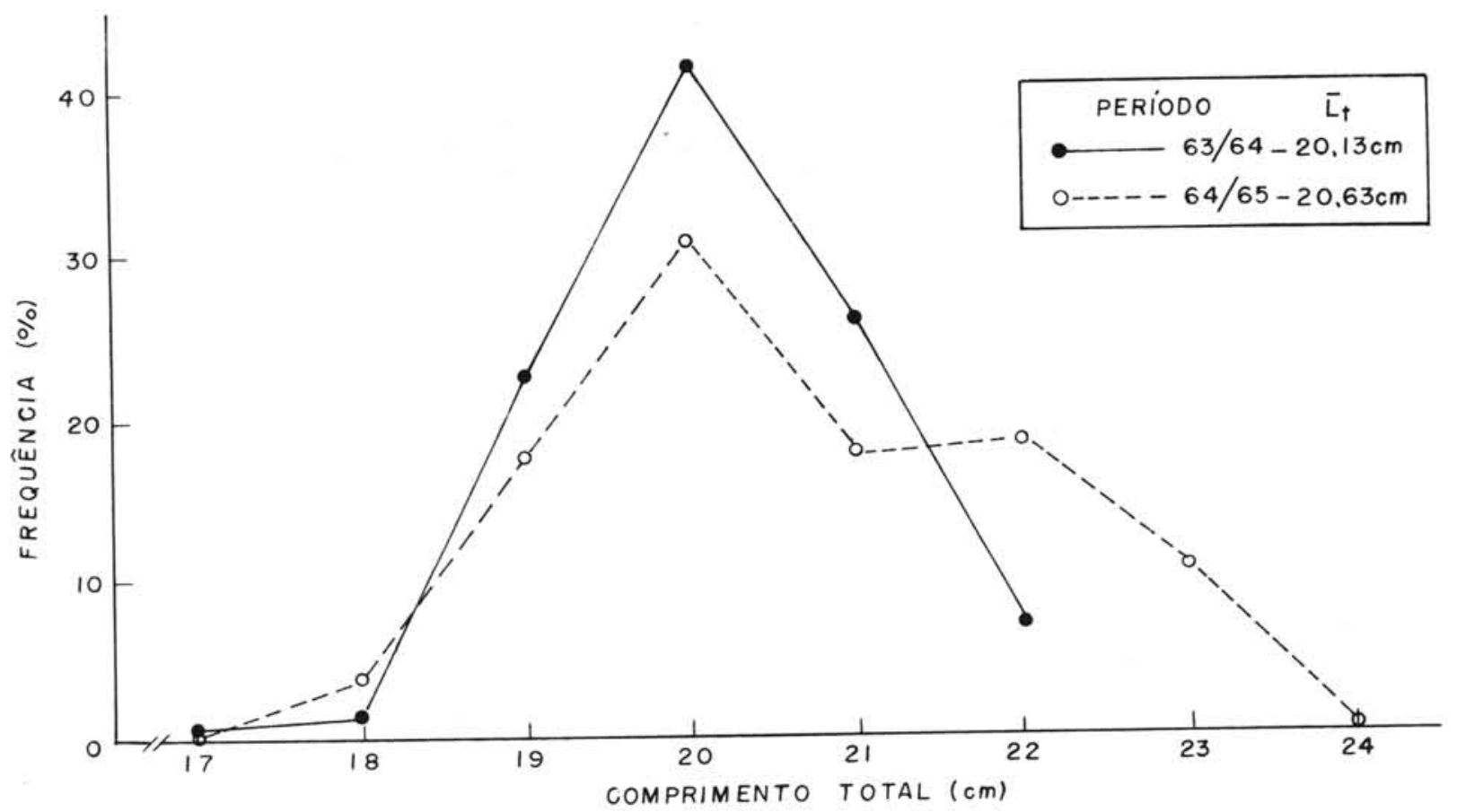

Fig. 9 - Distribuição porcentual de freqüência das classes de comprimento de fêmeas, durante os períodos de desova de $1963-64$ e 1964-65. 


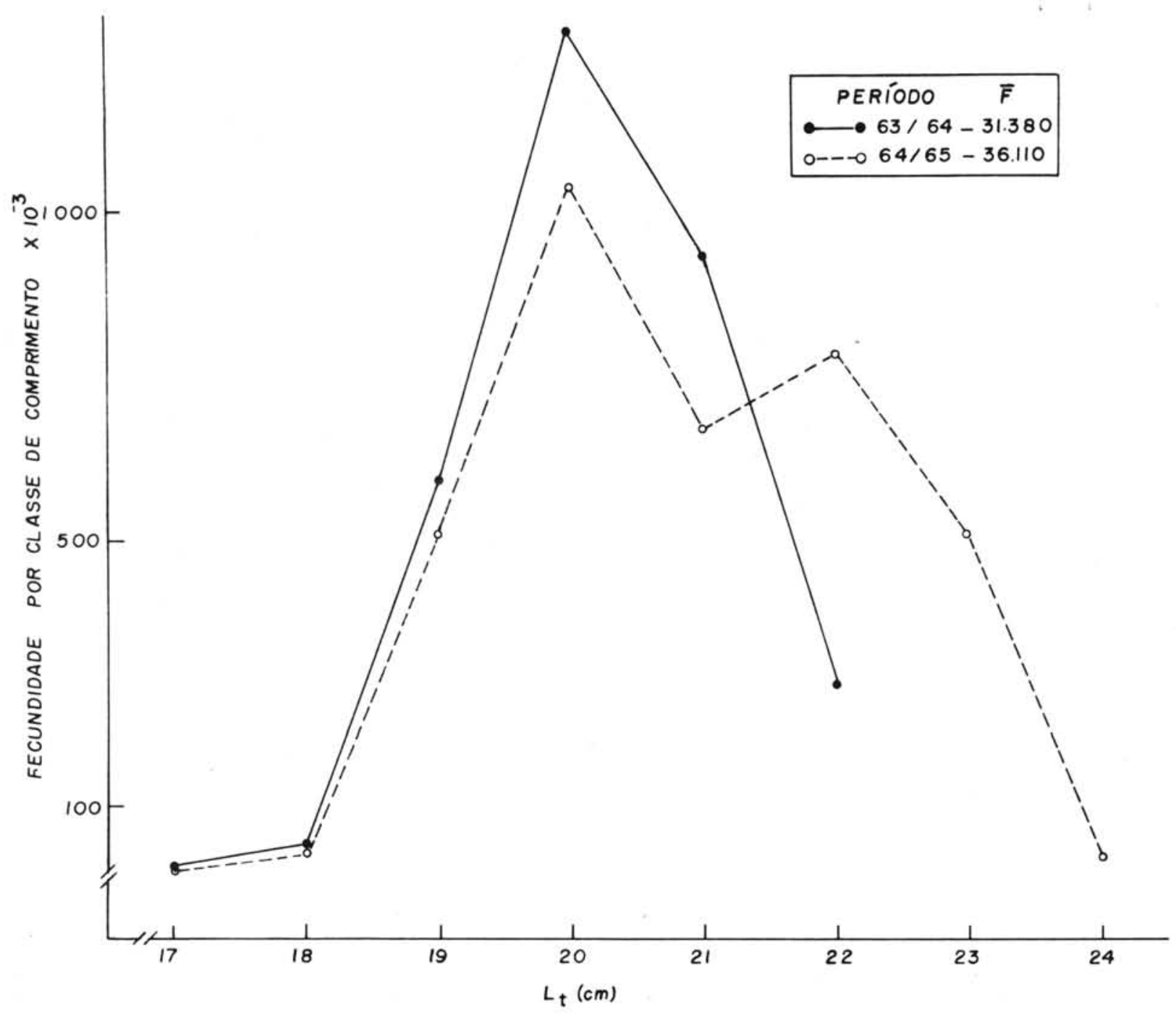

Fig. 10 - Potencial reprodutivo relativo à 100 fêmeas, por classe de comprimento, para cada um dos períodos estudados.

\section{DISCUSSÃO}

0 período de reprodução de Sardinella brasiliensis estende-se durante todo o verão, de outubro a março (Moraes, 1963; Vazzoler \& Vazzoler, 1965), estando a ārea de desova localizada sobre a plataforma continental, até a linha de $100 \mathrm{~m}$ de profundidade, entre a Ilha de São Sebastião e Ilha Grande (Matsuura, 1971). 
Para Sardina pilchardus, Andreu (1951) concluiu pela ocorrência de uma única desova apesar da distribuição dos diâmetros dos óvulos ser polimodal. MacGregor (1957), para Sardinops caemulea da Califórnia, concluiu por uma só desova por ano, apesar de ocorrer mais de um grupo de ovocitos em desenvolvimento, o que havia levado Clark (1934) a sugerir mais de uma desova durante a época de reprodução. Murphy (1966) discute os resultados de MacGregor e Clark, concluindo que os dados desta ültima são mais aceitáveis, ocorrendo para $S$. caemulea, em média, a desova de três ou mais lotes de óvulos durante um período. Naumov (1959) define desovas total e parcelada e discute a caracterização de cada tipo, e para Clupea harengus harengus conclui pela ocorrência de desova total, sendo entretanto o período de desova muito longo, causado pela maturação não isocrônica dos ovocitos nos indivíduos da população.

Besnard (1950) sugeriu a ocorrência de desovas consecutivas em Sardinelza brasiliensis da região de Cananéia, litoral sul do Estado de São Paulo.

Os resultados por nós obtidos sugerem que para S. brasiliensis da ārea estudada a desova individual é do tipo total, ou seja, há eliminação apenas do grupo de óvulos mais desenvolvidos. Entretanto, durante o período de desova, as fêmeas não maturam todas ao mesmo tempo, ocorrendo maturação e desovas sucessivas de grupos de indivíduos ou cardumes, o que determina um período de desova prolongado. Tal sugestão é reforçada pela ocorrência de fêmeas em distintas fases do estādio $C$ durante a época de reprodução, e pelas observações de Matsuura (1971) de ovos em diferentes fases de desenvolvimento na ārea de desova, admitindo a existência de vārios grupos de desova.

Desse modo fica confirmada a sugestão de Besnard (1950), e demonstrado que as desovas sucessivas resultam de desovas totais de diferentes cardumes, e não desovas sucessivas dos mesmos individuos componentes de um cardume.

Variações no tipo de desova são determinadas por diferentes condições ecológicas durante a reprodução. As espécies que apresentam desova parcelada possuem capacidade de adaptação mais desenvolvida e fecundidade mais elevada, assegurando a conservação da espécie (Nikolsky, 1963). 
Bolm Inst. oceanogr., S Paulo, 25, 1976

Para Micropogon furnieri e Macrodon ancylodon constatamos a ocorrência de desova parcelada (Vazzoler 1963, 1969, 1971; Yamaguti, 1967). Esses dois Sciaenidae apresentam ampla distribuição geográfica, ocupando ambientes tropicais, sub-tropicais e temperado-quentes, em toda a costa brasileira, com conseqüente divisão dessas espécies em populações distintas com épocas e 1ocais de desova diferentes (Vazzoler, 1971; Yamaguti, 1971), o que explicaria a ocorrência de desova parcelada.

Em S. brasiliensis a ārea de distribuição mais restrita $\left(23^{\circ} \mathrm{S}\right.$ a $\left.28^{\circ} \mathrm{S}\right)$ e, principalmente, a desova estreitamente relacionada a uma área de água fria de ressurgência (Matsuura, 1971), possibilitariam a ocorrência de desova total, com maturação sucessiva de grupos de indivíduos, o que representaria uma adaptação à competição pelos locais de desova e pelo alimento de larvas e jovens, dada a pequena extensão da área de desova (Matsuura, op. cit.).

Naumov (1959) discute a importância do índice de maturidade como indicador do estado biológico do peixe; para seu cálculo considera a relação entre peso da gônada e peso total do peixe. Entretanto, quando o período de desova é prolongado, o peso do peixe sofre marcada alteração; essas mudanças envo1vem o ganho em peso pelas gônadas às expensas dos tecidos do corpo. A mudança não é apenas uma transferência de uma parte para a outra, sendo que o peso total das gônadas mais o do corpo, também diminui. Assim, em tais casos, o índice deve ser baseado no peso do peixe sem as gônadas (peso do corpo), não podendo ser esperada uma relação muito íntima.

0 índice gonadal expressa a condição das gônadas, refletindo o estado dos ovārios em relação ao armazenamento de reservas.

Constatamos que para S. brasiliensis, dentro de um mesmo período, os valores dos índices gonadal e de maturidade para cada fase são estatisticamente distintos. Isso poderia sugerir sua utilização como um fator de caracterização do grau de desenvolvimento dos ovários. Entretanto, constatamos também que, para uma mesma fase, os índices são significativamente diferentes entre os dois períodos. Desse modo, tais índices, isolados, não podem ser utilizados para a determinação do estádio de maturidade do peixe.

Tanto os valores do índice de maturidade como do gonadal foram mais elevados durante o período 1964-65, o que sugere que nesse período as fêmeas 
encontravam-se em melhores condições. Constatamos também valor mais elevado para o fator de condição médio da população, em 1964-65. Isso reflete melhores condições alimentares dos peixes durante esse período.

Quando o alimento é mais abundante, o peixe cresce mais rápido e o aumento em peso leva a uma melhor condição do que quando o alimento é escasso. Melhoria na nutrição leva não apenas a crescimento mais rápido, mas também a fecundidade mais elevada. Variações na densidade da população, devidas à exploração ou a grande mortalidade de larvas, podem levar a um aumento na disponibilidade de alimento para os sobreviventes. Assim, a quantidade de alimento disponíve1, que por sua vez está relacionada com a densidade da população, é o fator mais importante (Bagenal, 1966; Nikolskii, 1969).

MacGregor (1959) estabeleceu para Sardinops caemilea uma alta correlação positiva entre fator de condição e comprimento do peixe. Apesar de nossos dados referirem-se apenas a dois períodos, constatamos um aumento do comprimento médio das fêmeas, acompanhado de aumento do fator de condição. 0 mesmo autor estabeleceu a ocorrência de correlações inversas entre fator de condição e tamanho da população, admitindo ser esta uma relação de causa e efeito, e entre comprimento médio e tamanho da população. Se tais relações forem vālidas para S. brasiliensis, como a primeira, no período 1964-65 a população seria menor que no anterior, sendo o potencial reprodutivo mais elevado devido ao aumento da fecundidade relativa e do tamanho dos peixes.

A ocorrência de valores mais elevados da fecundidade por classe de peso das gônadas durante 1963-64 é explicada pelo fato de nesse período os óvulos terem tamanhos menores; assim, o nümero de óvulos por grama de ovārio é mais elevado. Esse fato indica que tal relação não é útil, nem aconselháve1, para a estimativa da fecundidade em períodos distintos, tendo-se por base relação estabelecida para um determinado período. Para M. fumieri (Vazzoler, 1969) ta1 relação tambēm não se mostrou adequada para previsão da fecundidade.

A variação, em níveis estatísticos significativos, da fecundidade de um período para o outro seria explicada pela variação das condições alimentares, sugerida pelos índices de condição dos peixes (gonadal, maturidade e fator de condição), que sugerem terem sido as condições ambientais mais favoráveis durante o período 1964-65. 
A variação do fator alimento reflete-se tanto sobre a fecundidade em sí (número de óvulos), como no tamanho dos óvulos. Para nossos dados, durante o período de suposta maior disponibilidade de alimento (1964-65) foi verificado nível mais elevado da fecundidade e óvulos maiores.

E interessante ressaltar, e frizar, que apesar dos índices e relações utilizadas neste tipo de estudo, estabelecidos com o auxílio de tratamento matemático dos dados, terem um significado biológico, os organismos estão constantemente sob a ação de fatores intrínsecos e extrínsecos, que determinam variações dos processos biológicos, e conseqüentemente de tais índice e relações, que não podem, portanto, ser vistos como fixos, mesmo de um período para outro. Sua utilização deve sempre estar associada a observações puramente biológicas, servindo apenas como "auxiliares" na determinação ou avaliação de um processo biológico qualquer.

\section{RESUMO}

1) Sardinelza brasiziensis apresenta desova individual do tipo total; entretanto as fêmeas desovantes não maturam todas ao mesmo tempo, ocorrendo maturação e desovas sucessivas de grupos de indivíduos (cardumes), o que determina um período de desova prolongado;

2) Durante o período de desova de 1964-65 foram constatados valores para os índices de maturidade e gonadal, e para o fator de condição, mais elevados que durante 1963-64, o que sugere melhores condições alimentares durante tal período;

3) Os pesos médios por classe de comprimento, para as fêmeas, também foram mais elevados durante 1964-65, bem como o comprimento médio, a fecundidade média por fêmea e o potencial reprodutivo relativo;

4) Os valores dos índices considerados foram distintos dentro de um mesmo período, entre as várias fases, mas também variaram significativamente para uma mesma fase, entre os dois períodos, indicando não poderem ser utilizados como fator isolado para a caracterização do grau de desenvolvimento dos ovārios; 
5) As relações entre fecundidade e comprimento total, peso total, peso das gônadas e peso do corpo mostraram-se significativamente diferentes entre os dois períodos;

6) 0 tamanho dos óvulos, para uma mesma fase, variou de um período para o outro, sendo mais elevado durante 1964-65;

7) Os resultados mostram que, apesar dos índices e relações terem um significado biológico, referem-se a organismos vivos submetidos à ação do meio ambiente variāvel, e não podem ser encarados como fixos; sua utilização deve ser associada a observações puramente biológicas, servindo apenas como "auxiliares" na determinação ou avaliação de um processo biológico qualquer.

\section{SUMMARY}

1) The results show that the individual spawning of Sardinella brasiliensis is total, but several spawning groups occur, spawning consecutively during the reproduction period, which explains the relatively extended duration of the species spawning;

2) During the 1964-65 spawning period, the maturation and gonadal indexes as well as the condition factor values were higher than those recorded for 1963-64, suggesting better food conditions in the first period;

3) The mean weights for length class, the mean length, the mean fecundity and the relative spawning power for females were also higher in 1964-65;

4) Maturation and gonadal indexes values recorded, differed from one period to the other, from one phase of gonadal development to the other and from one phase of the period to the corresponding one in the other period;

5) Fecundity/ total length, total weight, ovarian weight and body weight relations differed statistically from one period to the other;

6) The size of the eggs of each phase varied from one period to the other and was greater during 1964-65;

7) The results show that although the indexes recorded are biologically meaningful, they should not be considered as steady values and used to 
characterize the species maturity and fecundity grades, because they represent biological processes which are closely dependent upon environmental condictions.

\section{B IBLIOGRAFIA}

ANDREU, B. 1951. Consideraciones sobre el comportamiento del ovario de la sardina (Sardina pilchardus Walb.) en relación con el proceso de maduración y de freza. Boln Inst. esp. Oceanogr., 41:1-16.

BAGENAL, T. B. 1966. The ecological and geographical aspects of the fecundity of the plaice. J. mar. biol. Ass. U.K., 46(1):161-186.

BESNARD, W. 1950. Nota preliminar sobre uma particularidade de Sardinella aurita Cuv. \& Val., da costa brasileira. Bolm Inst. paul. Oceanogr., 1(1):69-80.

CIECHOMSKI, J. D. de 1967. Caracter de1 desove y fecundidad de la merluza argentina, Merluccius merluccius hubbsi, del sector bonaerense. Boln Inst. Bio1. mar., (13):5-30.

CLARK, F. N. 1934. Maturity of California sardine determined by ova diameter measurements. Fish Bu11. Calif., 42:1-49.

FONTANA, A. \& LeGUEN, J. C. 1969. Étude de la maturité sexuelle et de la fecundité de Pseudotolithus (Fonticulus) elongatus. Cah. ORSTOM, sér. Océanogr., ?(3):9-19.

MacGREGOR, J. S. 1957. Fecundity of the Pacific sardine (Sardinops caemilea). Fishery Bull. Fish Wild1. Serv. U.S., 57 (121):427-449.

1959. Relation between fish condition and population size in the sardine (Sardinops caemulea). Fishery Bull. Fish Wild1. Serv. U.S., 60(166):215-230.

MATSUURA, Y. 1971. A study of the life history of Brazilian sardines, Sardinella aurita. I. Distribution and abundance of sardine eggs in the region of Ilha Grande, Rio de Janeiro. Bolm Inst. oceanogr., S Paulo, 20(1):33-60.

MORAES, M. N. de 1963. Observações sobre a biologia da sardinha e sua captura ao longo da costa sul do Brasil, de 1959 a 1961 . Bolm Ind. anim., n.s., 21 (nọ único):3-16.

MURPHY, G. I. 1966. Population biology of the Pacific sardine (Sardinops caemlea). Proc. Calif. Acad. Sci., 34(1):1-84. 
NAUMOV, V. M. 1959. The ovogenesis and ecology of the sexual cycle of the Murmansk herring (Clupea harengus harengus L.). Spec. scient. Rep. U.S. Fish Wildl. Serv., Fisheries, 327:203-262.

NIKOLSKY, G. V. 1963. The ecology of fishes. London, Academic Press, 352 p.

NIKOLSKII, G. V. 1969. Theory of fish population dynamics as the biological background for rational exploitation and management of fishery resources. Edinburg, Oliver \& Boyd, 323 p.

SIMPSON, A. C. 1951. The fecundity of the plaice. Fishery Invest., Lond., ser. II, $17(5): 3-27$.

VAzZOLER, A. E. A. de M. 1963. Sobre a fecundidade e a desova da pescada-foguete. Bolm Inst. oceanogr., S Paulo, 13(2):33-40.

1969. Micropogon fumieri: fecundidade e tipo de desova. Bolm Inst. oceanogr., S Paulo, 18:27-32.

1971. Diversificação fisiológica e morfo1ógica de Micropogon fumieri (Desmarest, 1822), ao sul de Cabo Frio $\left(23^{\circ} \mathrm{S}\right)$, Brasil. Bolm Inst. oceanogr., S Paulo, 20(2):1-7C.

\& VAZZOLER, G. 1965 . Relation between condition factor and sexual development in Sardinella aurita (Cuv. \& Val., 1847). Anais Acad. bras. Ciênc., 37 (sup1.):353-359.

YAMAGUTI, N. 1967. Desova da pescada-foguete, Macrodon ancyZodon. Bolm Inst. oceanogr., S Paulo, 16(1):101-106.

1971. Diferenciação geogrä́fica de Macrodon ancyZodon (Bloch \& Schneider, 1801) na costa brasileira, entre as latitudes $18^{\circ} 36^{\prime} \mathrm{S}$ (Conceição da Barra, ES) e 32\%10'S (Barra do Rio Grande, RS). Tese de doutoramento. Universidade de São Paulo, Instituto de Biociências. (Não publicada). 